\title{
A FORMAÇÃO MÉDICA NA CONSTRUÇÃO DA COMPETÊNCIA E CIDADANIA
}

Regina Monteiro*

SÍNTESE - Este artigo é parte do projeto de pesquisa "Formação médica na construção de competência e cidadania", que se propõe averiguar em que medida as demandas exigidas pelas transformações macro sociais em relação à instauração de competências estão sendo incorporadas pelo processo de formação desenvolvido na Faculdade de Medicina da PUCRS, contribuindo para o fortalecimento da cidadania.

PALAVRAS-CHAVE - formação, competência, cidadania.
ABSTRACT - This article is part of a research project called "Medical formation in the construction of competence and citizenship". It proposes to search in what the demands required by the macro transformations in society in relation to the establishment of competencies, have been incorporated in the process of formation developed in the Faculty of Medicine, PUCRS, and are contributing for the consolidation of citizenship.

KEY WORDS - formation, competence, citizenship.

\section{A formação médica no contexto atual}

A época atual é marcada por um extraordinário desenvolvimento da ciência e da tecnologia, pela globalização da economia e internacionalização do mercado, pelas novas formas de governo com enfraquecimento do modelo do Estado-Nação.

No cenário nacional assistimos à crescente redução da participação do Estado na prestação dos serviços de saúde e, conseqüentemente, à privatização dos mesmos à mercê das regras do mercado; assistimos também ao desmantelamento do Sistema Único de Saúde, à proliferação de escolas médicas com fins comerciais e ao agravamento da exclusão de um imenso contingente da população da assistência básica.

As repercussões dessas mudanças no campo da saúde e, particularmente, da medicina, caracterizam-se pelo uso abusivo e indiscriminado de tecnologia, redundando no exercício de uma medicina mercantilizada, com base éticohumanista deficiente. A formação médica, por sua vez, está hoje quase totalmente desvinculada dos reais problemas de saúde da população, sejam eles de ordem política, econômica, ética ou mesmo da saúde coletiva.

* Professora adjunta do Departamento de Medicina Social da Faculdade de Medicina (FAMED) da PUCRS. 
Nesse contexto, a necessidade de introduzir mudanças no ensino médico, principalmente no que se refere à sua dimensão social, vem sendo apontada e discutida, em nível mundial, já há duas décadas.

O ano de 1978, com a Conferência de Alma Ata (OMS), é um marco histórico no movimento de reorientação do ensino médico, tendo como ponto de partida a questão da adequação da formação médica à realidade sócio-sanitária dos países em desenvolvimento.

Em 1988, a I Conferência Mundial sobre Educação Médica, realizada em Edimburgo, Escócia, reforça a questão no seu documento final fazendo o apelo:

"Nos comprometemos e exortamos outros para que se juntem a nós em um programa sólido e organizado, a fim de mudar o perfil da educação médica, de modo que possa verdadeiramente atender as necessidades definidas pela sociedade em que está situada" (ABEM, 1988, p. 4).

A partir de então, em diversos momentos e fóruns, em nível mundial e nacional, como as Conferências Mundiais promovidas pela Federação Mundial para a Educação Médica, os Congressos Nacionais da Associação Brasileira de Educação Médica, os documentos do MEC sobre Educação Médica, entre outros, vem sendo afirmada a necessidade de que a formação médica seja comprometida com as demandas sociais e baseada na integração multiprofissional e interdisciplinar.

Mais recentemente, foi desenvolvido, no Brasil, entre 1991 e 1997, um projeto de avaliação do ensino médico pela CINAEM (Comissão Interinstitucional Nacional de Avaliação do Ensino Médico), do qual participaram 50\% das Escolas Médicas Nacionais. Os resultados obtidos revelam, entre outros, que a estrutura curricular é defasada e com baixo comprometimento em relação às necessidades sociais, predominantemente tecnocêntrica, privilegiando a formação de especialistas e, conseqüentemente, preocupando-se muito pouco com a prática interdisciplinar.

Pode-se perceber, portanto, que não obstante os vinte anos de discursos, 0 movimento de reorientação do ensino médico ainda não foi capaz de produzir mudanças significativas na formação do médico.

\section{A concepção de formação, competência e cidadania}

A formação é entendida como um conjunto de ações que visam a orientação e a integração do homem ao contexto social, envolvenđo fatos referentes ao conjunto da vida, à totalidade das relações sociais. Caracteriza-se como uma atividade social de transmissão e aquisição de conhecimentos, comportamentos e atitudes que não se restringem apenas à escola, mas está associada a fatos e mudanças estruturais e conjunturais nos níveis econômico, político e social.

No âmbito da formação, a competência vem sendo apontada atualmente como a categoria que sintetiza as alterações necessárias à construção do novo perfil de trabalhador. Daí tomar-se, hoje, esta categoria como expressão de uma forma de formar desencadeada por uma diversidade de práticas sociais que, ao implicar inúmeros saberes, tem condições de instaurar a formação exigida pelo contexto atual. 
Neste sentido, enquanto dimensão do processo de formação, a competência pressupõe: um conjunto de saberes e conhecimentos que visam à qualificação profissional; a capacidade de articular, reconstruir e atualizar os inúmeros saberesconhecimentos para interagir na dinâmica do mundo do trabalho e da vida social, enquanto cidadão, e o desenvolvimento de habilidades e potencialidades dos indivíduos com ênfase na criatividade, capacidade crítica, autonomia, compromisso, espirito de iniciativa e flexibilidade perante o novo.

Portanto, o processo de formação engloba saberes que se referem não somente àqueles relacionados a uma tarefa específica. Passam a valer também os saberes sociais, informais, da experiência e tudo o que constitui acúmulo do trabalhador e que possa ser mobilizado no exercício do trabalho, garantindo-lhe maior versatilidade e flexibilidade resultando num desempenho mais eficaz.

O conceito de cidadania, enquanto direito a ter direitos, tem se prestado a diversas interpretações. Entre elas, tornou-se clássica a concepção de T. H. Marshall, citado por Liszt Vieira, que considera a cidadania composta dos direitos civis, politicos e sociais (Vieira, 1997).

Os direitos civis correspondem aos direitos individuais de liberdade, igualdade, propriedade, de ir e vir, direito à vida, segurança, etc. Os direitos políticos dizem respeito à liberdade de associação e reunião, de organização política e sindical, à participação política e eleitoral, ao sufrágio universal, etc. Os direitos sociais, econômicos ou de crédito são os direitos ao trabalho, saúde, educação, aposentadoria, seguro-desemprego, enfim, a garantia de acesso aos meios de vida e bem-estar social.

Na segunda metade do nosso século, surgiram os chamados "direitos de terceira geração" que têm como titular não o indivíduo, mas grupos humanos como o povo, a nação, coletividades étnicas ou a própria Humanidade. É o caso do direito à autodeterminação dos povos, direito ao desenvolvimento, direito à paz, direito ao meio ambiente saudável, etc. Já se fala hoje de "direitos de quarta geração", relativos à bioética, para impedir a destruição da vida e regular a criação de novas formas de vida em laboratório pela engenharia genética.

Existem outros ângulos de conceber a cidadania, por exemplo, a definida como competência humana de fazer-se sujeito, para fazer história própria e coletivamente organizada. Para o processo de formação dessa competência, alguns componentes são cruciais, como organização política, identidade cultural, informação e comunicação, destacando-se, acima de tudo, o processo emancipatório.

A noção de cidadania, aqui considerada, contempla o direito a ter direitos e tem uma proposta de relações sociais mais igualitárias, a partir de novas formas de aprendizagem social e de convivência entre todos os cidadãos. Entre esses direitos inclui-se o próprio acesso a saberes e práticas sociais que permitam o desenvolvimento da subjetividade e a construção de outros tipos de convivência social e novas relações sociais.

Atualmente, diante de fenômenos crescentes como o da globalização da economia, a degradação ambiental global, entre outros, que apontam à necessidade de regulação politica global e à possibilidade de desenvolvimento de uma sociedade civil global, emerge a noção de cidadania planetária, enraizada em valores humanos universais. 
A possibilidade de articulação entre essas categorias, formação para a competência e para a cidadania, considera que ambas se baseiam no desenvolvimento da subjetividade do cidadão compreendida nas dimensões individual e coletiva e têm como pontos em comum: a diversificação do aporte de saberes, a abordagem interdisciplinar, a articulação entre cognição-afeto e entre teoria-prática e ainda o processo e as relações democráticas entre os agentes sociais, formadores e formandos.

\section{Modelos alternativos à formação médica atual}

O modelo de formação médica centrada na comunidade situa-se nesse enfoque, conforme destaca a OMS:

“O conceito de educação centrada na comunidade representa uma tendência importante dentro dos métodos contemporâneos de educação. Integra a educação e o trabalho produtivo dentro do processo de aprendizagem. É um produto da evolução dos métodos educacionais, em geral, e da educação de terceiro nível em particular. Ao mesmo tempo é fonte de novas idéias nas esferas da política educacional, dos métodos educacionais, da formulação de planos de estudo e outros aspectos da educação" (OMS, 1987, p. 11-13).

A educação centrada na comunidade vincula-se aos esforços de fazer os estudantes e as instituições de ensino participarem no desenvolvimento nacional. Em vista deste objetivo, a participação em atividades de educação centrada na comunidade:

- dá aos estudantes um sentido de responsabilidade social, pois lhes permite compreender claramente as necessidades de uma comunidade local e os problemas que esta e o pais, em seu conjunto, têm. Compreendem assim a relação recíproca entre a saúde e outros fatores que interferem no desenvolvimento da comunidade;

- coloca os estudantes em condições de vincular o conhecimento teórico com a formação prática e os prepara para a vida, para a sua futura integração no meio de trabalho, ao mesmo tempo que estimula a sua produtividade. Os estudantes encontram-se em melhores condições de administrar suas carreiras e de reconhecer e resolver os tipos de problemas que requerem um enfoque multidisciplinar;

- facilita a atuação do processo educacional na medida em que, continuamente, coloca os estudantes diante da realidade, ajudando-os a elucidar e encontrar soluções para os problemas. Deste modo, a educação contribui para o desenvolvimento.

No ensino médico, a literatura consultada argumenta ainda a importância deste enfoque destacando, entre outros, os seguintes aspectos:

- o ensino centrado em comunidade traz um aprimoramento técnico na formação médica em virtude da aproximação dos graduandos do contexto sóciosanitário da sociedade e, com isso, habilita-os à resolução de problemas de saúde não somente individuais mas também coletivos;

- desenvolve a dimensão ética da prática profissional e a capacidade crítica dos alunos, pois através da reflexão e argumentação científica possibilita a passagem de uma consciência ingênua a uma consciência que contemple a ética em todas as dimensões profissionais. 
Em síntese, o ensino centrado em comunidade enquanto aprendizado ativo, baseado em experiências contextualizadas dos determinantes sociais do processo saúde-doença, pode oportunizar a construção de uma nova identidade e desenvolver maior competência na prática profissional. Desta manieira, é possivel presumir o quanto esta modalidade de formação pode contribuir para a construção da cidadania.

\section{Considerações finais}

O movimento de reorientação da formação médica provoca uma ruptura com o paradigma tradicional, sugerindo o deslocamento do foco do ensino do hospital universitário para a rede básica em comunidade. A Faculdade de Medicina da PUCRS tem criado espaços de extensão que aproximam os acadêmicos do contexto sócio-sanitário da sociedade, enfocam um aprendizado ativo baseado em experiências contextualizadas e oportunizam o desenvolvimento de habilidades na solução de problemas.

Há, portanto, evidências de que a formação médica vem incorporando algumas demandas exigidas pelas transformações sociais. Contudo, somente o processo investigativo permitirá perceber essa realidade e a tendência de tal processo.

\section{Referências bibliográficas}

ALMEIDA, Márcio José de. "Ensino médico e saúde no Brasil: panorama atual e perspectivas futuras das suas políticas”. In: Divulgação Saúde para Debates, Londrina, CEBES, n. 5, ago. 1991, p. 9-12.

AMRIGS. Associação Médica do Rio Grande do Sul. pesquisa o perfil do médico no Estado. Jornal AMRIGS, maio 1991.

CINAEM. Comissão Interinstitucional Nacional de Avaliação do Ensino Médico. Avaliação do Ensino Médico no Brasil - Relatónio Geral. Brasilia, maio 1997.

DEMO, Pedro. Pesquisa: principio científico e educativo. São Paulo: Cortez, 1990.

. Cidadania Menor. Petrópolis: Vozes, 1991.

Cidadania tutelada e cidadania assistida. Campinas: Autores Associados, 1995.

DESAULNERS, Julieta Beatriz Ramos (org.). Formação \& trabalho \& competência. Porto Alegre: EDIPUCRS, 1998.

OMS. Organização Mundial da Saúde. La educación del personal de salud centrada en la comunidad. Informes Técnicos, n. 746.

VERITAS. Porto Alegre, EDIPUCRS, v. 41, jun. 1996, p. 201-376.

— Porto Alegre, EDIPUCRS, v. 42, jun. 1997, p. 177-472.

VIEIRA, Liszt. Cidadania e globalização. Rio de Janeiro: Record, 1997. 